\title{
Maternal-fetal attachment: what we know and what we need to know
}

Keywords: attachment, development, maternal fetal relation, pregnancy

\section{Introduction}

The attachment theory was first introduced by John Bowlby in 1960s about the mother-child bond. ${ }^{1}$ He defined attachment as "a set of internal behaviors that would cause the infant to become closely related to his/her main caregiver, who is usually the mother". ${ }^{2}$ Although this concept was first introduced for the post-partum period, but it is believed that attachment starts long before birth, during pregnancy. ${ }^{3-5}$ In other words, attachment starts when mother finds out about her pregnancy and this is the real start point for fetus' dialog with his/her surrounding world. ${ }^{7}$ Cranley has expressed mother's attachment as her enthusiasm in behaviors for interacting with her fetus $^{8}$ and Muller believed that it is more than just a behavior and has defined as a unique relationship between the mother and her fetus. ${ }^{9}$ The common characteristic between all of these definitions is emphasis on the importance of maternal-fetal relationship. ${ }^{10,11}$ Development of this relationship is important due to its role in creation of attachment after birth. ${ }^{12,13}$ Some researchers have reported that mother's attachment to the fetus would develop during pregnancy and it would help her prepare for transition to the motherhood period. ${ }^{14,15}$ Some studies have shown that prenatal attachment is an important factor in predicting post-partum attachment behaviors, ${ }^{6}$ it is associated with mother-infant post-partum interactions and communications ${ }^{12}$ and it has an important role in the health of the pregnant mother and her fetus. ${ }^{11}$ Attachment, which is one of the essential needs of human beings, would act like an invisible connection and maintain a close relation between the mother and the child, ${ }^{16}$ is considered an important part of child's development, ${ }^{4,18-24}$ and would develop a sense of trust in the child. ${ }^{5}$ Results of studies conducted on human beings and other species have revealed that care deprivation has a major effect on the evolution of regulatory system and coping with stress. Mother's reaction to child's stress is considered an important source for coping; therefore infants with sensitive and respondent parents would learn that at the time of stress, parents are always available and it would be more chance for them to have secure attached relationship with their parents in the future. But infants with insensitive parents would learn that parents are not always available at the time of stress and crisis; so they would probably develop an insecure relationship with their parents. ${ }^{25}$

Inappropriate development of attachment would have an adverse effect on the regulating part of child's right brain; different related studies have reported lower emotional and mental development, weak social interactions, school refusal, and more aggressive and hostile behaviors during childhood, behavioral disorders during adolescence and more tendencies toward drug abuse during adulthood. ${ }^{11,26}$

Furthermore, mother's attachment to her fetus has a close relation with other important processes. Mele is believed that being related and attached to the fetus and sacrificing for him/her is a responsibility that mothers should be committed to from the pregnancy period. ${ }^{27}$ Mother's commitment, attachment and preparation for taking care of their child during pregnancy are the main parts of the motherhood
Volume 2 Issue 5 - 2017

\author{
Kobra Salehi,' Shahnaz Kohan² \\ 'School of Nursing and Midwifery, Isfahan University of Medica \\ Sciences, Iran \\ ${ }^{2}$ Associated Professor of Reproductive Health, Nursing and \\ Midwifery Care Research Center, Iran
}

\begin{abstract}
Correspondence: Shahnaz Kohan, Associated Professor O Reproductive Health, Nursing and Midwifery Care Research Center, Faculty of Nursing and Midwifery, Isfahan University of Medical Sciences, Isfahan, Iran, Tel 00989133191322 \& 00983 |37927532, Fax 00983|36699398, Email Kohan@nm.mui.ac.ir
\end{abstract}

Received: August 14, 2017| Published: August 21, 2017

process and for reaching the maternal identity. ${ }^{27,28}$

Since the presentation of this concept in the early 1980s many studies have been conducted in this issue. Most of the studies have evaluated attachment in the form of mother-infant postpartum interactions, ${ }^{29-32}$ but a few has been dedicated to studying the subjective world of parents about their fetus during pregnancy ${ }^{33}$ and mother's attachment to her fetus is not well recognized; ${ }^{34}$ so that most of the studies about attachment during pregnancy are cross-sectional and related to the third trimester. ${ }^{1,6,11,35-42}$ Studying attachment during a limited time period would not be able to provide comprehensible information about its related factors and outcomes, ${ }^{40}$ while, according to evidences, this relationship could be affected by different factors like nationality, cultural, mental and social conditions and individual's past; namely women who have not experienced a secured attachment during their childhood might encounter problems in developing an attachment to their infant. ${ }^{13,40}$ Muller also believed that pregnant mother's experience of attachment to her own mother during childhood, would affect her future attachments to the family, spouse and friends and this process is effective on accepting the pregnancy and attachment to the fetus. ${ }^{31}$ In the other words, the current living condition of people is rooted in their past and attachment as a unique process is affected by personal factors, individual's believes and past, environmental and cultural factors; attachment could also be affected by different issues like mental condition, social support, mother's age, gravida and etc. which vary among different cultures. ${ }^{42}$

The review of literature about related factors to prenatal attachment among different groups of pregnant women have emphasized that despite the numerous evaluations and different methods of studies, further studies are required in this field. ${ }^{43}$ For example social support is one of the issues that its effect has not been conclusively determined. ${ }^{26}$ Also longitudinal studies are required to evaluate the effect of attachment during pregnancy on mothers' mental health, parental behaviors and the consequences of infancy. This information could not be obtained through cross-sectional studies and through one episode of data collection ${ }^{31}$ and more studies are needed to provide us a perspective of the mother-infant relation over time. ${ }^{44}$ 
Walsh has stated that predictive factors for mother-fetal relationship have yet not been determined conclusively ${ }^{45}$ By determining mothers' attachment style and the status of maternal-fetal attachment during pregnancy, in time interventions and educations could be planned for improving these interactions and consequently improve the motherchild attachment during the sensitive period of growth. ${ }^{46}$ The prenatal period is a proper chance for evaluating maternal-fetal attachment. ${ }^{11}$ Since all of the mother's behaviors, actions and thoughts during pregnancy could have more permanent effects on the fetus than any other period of child's life ${ }^{47}$ and also since pregnancy is considered a critical period in the development, therefore it is necessary to evaluate mother's attachment to her fetus more accurately. Studying attachment during pregnancy would provide us a chance to learn more about this process. According to Bowlby studying this issue would help us understand and cope with the psychological problems during and after pregnancy. ${ }^{11}$

Therefore considering the importance of attachment in child's development and mother's health and various factors that are effective on this matter and also lack of necessary information in this regard in our country, the research team decide to conduct this study to evaluate maternal-fetal attachment during pregnancy and its postpartum consequences on mother-infant relationship. This process should be studied during pregnancy and also after delivery so that the effect of related factors and the changes in attachment over time could be determined and comprehensive information about the effective underlying conditions on this issue would be gathered. Such study would reveal many facts about attachment and its related underlying and mediator conditions. Awareness about prenatal attachment is important in the health of pregnant mothers and their children and also in finding optimal compatibility with motherhood. The collected information not only would increase the perception of the medical team about the process of attachment, but it would also provide the possibility for planning proper interventions to improve maternalfetal relationship.

\section{Acknowledgements}

This study was derived from an approved and sponsored research project by Isfahan University of Medical Sciences (N.395362). Authors acknowledge Vice chancellor for research, Isfahan University of Medical Sciences, IRAN.

\section{Conflict of interest}

Author declares that there is no conflict of interest.

\section{References}

1. Ossa X, Bustos L, Fernandes L. Prenatal attachment and associated factors during the third trimester of pregnancy in Tumeco, Chile. Midwifery. 2012;28(5):689-696.

2. Bowlby J. Attachment and loss (Vol. 1). New York: Basic Books; 1969.

3. Sadeghi M, Mazaheri A. Comparement of attachment styles in mothers with and without history of fetus abortion (intentional and spantaneus). Fertility and Infertility Journal. 2007;8(1):60-69.

4. Sedgmen B, Mcmahon G, Carins D, et al. The impact of twodimensional versus three dimensional ultrasound exposure on maternalfetal attachment and maternal health behavior in pregnancy. Ultrasound Obstet Gynecol. 2006;27(3):245-251.

5. Gurol A, Palot S. The effects of baby massage on attachment between mother and their infants. Asian Nurs Res. 2012;6(1):35-41.
6. Perry D, Ettinger A, Mendelson T, et al. Prenatal depression predicts postpartum maternal attachment in low- income latina mothers with infants. Infant Behav Dev. 2011;34(2):339-350.

7. Ulrich H, Asim K. Pregnancy and loneliness:the therapeutic value of 3D/4D ultrasound. Psychology. 2014;5:744-752.

8. Cranley MS. Development of a tool for the measurement of maternal attachment during pregnancy. Nursing Research. 1981;30(5):281-284.

9. Muller ME. Development of the prenatal attachment inventory. West $J$ Nurs Res. 1993;15(2):199-215.

10. Doan H, Zimerman A. Conceptualizing Prenatal Attachment: Toward A Multidimensional View. Journal of prenatal and perinatal psychology and health. 2003;18:109-130.

11. Ustunsoz A, Guvenc G, Akyuz A, et al. Comparison of maternal and paternal fetal attachment in Turkish couples. Midwifery. 2010;26(2):1-9.

12. Dayton C, Levendosky A, Davidson W, et al. The child as held in the mind of the mother: The influence of prenatal maternal representations on parenting behaviors. Infant Mental Health Journal. 2010;31(2):220-241.

13. Mehran P, Simbar M, Shams J, et al. history of perinatal loss and maternalfetal attachment behaviors. Women and Birth. 2013;26(3):185-189.

14. Eswi A, Khalil A. Prenatal attachment and fetal health locus of control among low risk and high risk pregnant women. World Applied Sciences. $2012 ; 18(4): 462-471$

15. Beckett C, Taylor H. Human Growth and development. New Delhi, India; 2010.

16. Moghaddam Hoseini V, Jaafarnejadf F, Soltani-Far A. Impact of Maternal Attachment Style on Mother to Infant Attachment. Qom Univ Med Sci J. 2011;5(3):87-91.

17. Rees C. Thinking about children's attachments. Archives of Disease in Childhood. 2005;9(10):1058-1065.

18. Sroufe LA. Attachment and development: A prospective, longitudinal study from birth to adulthood. Attachment \& Human Development. 2005;7(4):349-367.

19. Dekleyn M, Greenberg M. Attachment and psychopathology in childhood. In: Cassidy J, Shaver P, editors. Handbook of attachment: Theory, research, and clinical applications. New York: Guilford Press; 2008.

20. Lyons-Ruth K, Jacobvitz D. Handbook of attachment: Theory, research, and clinical applications. In: Cassidy J, Shaver P, editors. Attachment disorganization: Genetic factors, parenting contexts, and developmental transformation from infancy to adulthood. New York: Guilford Press; 2008.

21. Weinfield N, Sroufe L, Egeland B, et al. Individual differences in infantcaregiver attachment: Conceptual and empirical aspects of security. In: Cassidy J, Shaver P. editors. Handbook of attachment: Theory, research, and clinical applications. New York: Guilford Press; 2008.

22. Barlow J, Svanberg P. Keeping the baby in mind: Infant mental health in practice. New York: Taylor \& Francis Group; 2009.

23. Parsons C, Young K, Murray L, et al. The functional neuroanatomy of the evolving parent-infant relationship. Progress in Neurobiology. 2010;91(3):241-220.

24. Wjik M, saridjan N, Ijzendoorn M, et al. Attachment depression and cortisol; Deviant patterns in Insecure-resistant and disorganized infanints. Dev Psychobiol. 2010;52(5):441-452.

25. Feldman JB. The Effect of Support Expectations on prenatal attachment: an evidence based approach for intervention on an adolescent population. Child and adolescents social work journal. 2007;24(3):209-235. 
26. Meleis A. Transition theory: Middle Range and Situation Specific Theories in Nursing Research and Practicies. New York: Springer Publishing Company; 2010.

27. Mercer RT. Becoming a mother versus maternal role attainment. J Nurs Scholarsh. 2004;36(3):226-232.

28. Raphael-Leff J. Psychological Processes of Childbearing. The Anna Freud Centre, London, UK; 2005.

29. Theran S, Levendosky A, Bogat A, et al. Stability and change in mothers' internal representations of their infants over time. Attachment \& Human Development. 2005;7(3):253-268.

30. Brandon A, Pitts S, Denton W, et al. A history of the theory of prenatal attachment. J Prenat Perinat Psychol Health. 2009;23(4):201-222.

31. Ammaniti M, Tambelli R, Odorisio F. Exploring maternal representations during pregnancy in normal and at-risk samples: The use of the interview of maternal representations during pregnancy. Infant Mental Health Journal. 2013;34(1):1-10.

32. Leva-Giroux R. Prenatal maternal attachment: the lived experience. USA: Doctor of nursing Sciences University of sandiego; 2002.

33. Eichhorn N. Maternal Fetal Attachment: Can Acceptance of Fetal Sentience Impact the Maternal-Fetal Attachment Relationship? Journal of Prenatal and Perinatal Psychology and Health. 2012;27(1):47-55.

34. Armstrong DS. Emotional distress and prenatal attachment in pregnancy after perinatal loss. Journal of nursing scholarship. 2002;34(4):339-345.

35. Zimerman A, Doan H. Prenatal attachment and other feeling and thoughts during pregnancy in three groups of pregnant women. Journal of prenatal and perinatal psychology and health. 2003;18:2.

36. Huth-Bocks A, Levendosky A, Bogat G, et al. The impact of materna charactristics and contextual variables on infant-mothr attachment. Child Dev. 2004;75(2):480-496.

37. Bielawska B, Siddiqui A. A study of prenatal attachment with Swedish and polish expectant mothers. Journal of reproductive and infant psychology. 2008;26(4):372-384.
38. Stemmle P. An exploration of maternal variables impacting infant attachment status among high risk pregnant adolescent. Doctor of Psychology, Palo Alto University, Californi, USA; 2010.

39. Mcfarland J, Salis Bury A, Battle C, et al. Major depressive disorders during pregnancy and emotional attachment to the fetus. Arch Women Ment Health. 2011;14(5):424-434.

40. Silvera A. Prenatal attachment in adolescent: relationship with maternity identify, parent and peer attachment and father of the baby. USA: Doctor of Psychology, Alliant International University. 2013.

41. Torshizi M. Different Dimensions of Maternal-Fetal Attachment Behaviors and Associated Factors in Pregnant Women Referred to Health Centers of Birjand, Iran. IJOGI. 2013;16(72):13-21.

42. Hobbs k. An invstigation into the relationships btween psychological functioning, engagement with obstetric services and prenatal attachment. A dissertation presented in partial fulfillment of the requirements for the degree Doctor of Psychology. University of Sheffield, UK; 2010.

43. Alhusen J, Gross D, Hayat M, et al. The influence of maternal- fetal attachment and health practices on neonatal outcomes in low- income urban women. Res Nurs Health. 2012;35(2):112-120.

44. Walsh J, Hepper EG, Marshall BJ. Investigating attachment, caregiving, and mental health: a model of maternal-fetal relationships. BMC Pregnancy and Child birth. 2014;14:383.

45. Tabaeh-Emami SH, Noori A, Malekpour M, et al. Effectiveness of Cognitive-Behavior Training for Mothers on Changing Maternal Behavior and Child's Insecure Attachment. Journal of Clinical Psychology. 2011;3(3):7-16.

46. Burke Ch. The effects of an 18-hours prenatal attachment program on maternal emotional attachment. A dissertation presented in partial fulfillment of the requirements for the degree Doctor of Psychology. USA: Capella University; 2007.

47. Davachi A, Khoramroodi R, Shahpoorian F, et al. Fetal touching! Does it improve maternal fetal or meternal newborn attachment? Journal of Iran Nursing. 2001;13:16-44. 